\title{
A aprendizagem colaborativa para a interdependência positiva no processo ensino-aprendizagem em cursos universitários
}

Collaborative apprenticeship for a positive interdependence in the teach-apprenticeship process in university courses

Marcella Zampoli Troncarelli*

Universidade Estadual Paulista Julio de Mesquita Filho

Adriano Antonio Faria** Universidade Tuiuti do Paraná

Resumo O objetivo central do presente estudo foi elencar e discutir as vantagens da Aprendizagem Colaborativa/Cooperativa (AC), como proposta de incremento educativo em cursos de graduação (Ensino Superior), no Brasil. O principal referencial teórico adotado foi a linha de estudo de Alcântara e colaboradores. Com base nas considerações apresentadas, no presente artigo, verifica-se que a AC é factível, dinâmica e atual, proporcionando inúmeras possibilidades de experiências exitosas para o aprendizado. A formação dos alunos ocorre de maneira participativa, articulada, reflexiva e socialmente contextualizada, contribuindo para a formação de profissionais completos que compreendem seu papel na sociedade. Desta forma, conclui-se que o presente artigo contribui para a divulgação e disseminação da $\mathrm{AC}$ para um maior número de instituições de ensino superior brasileiras.

PALAVRAS-CHAVE: Ensino-aprendizagem, Graduação, Interação.

Abstract The central objective of this study was to list and discuss the advantages of Collaborative / Cooperative Learning (CL) as a proposed increase in undergraduate education (Higher Education) in Brazil. The main theoretical reference adopted was the line of study of Alcantara et al. Based on the considerations presented in this article, it is possible to conclude that CL is feasible, dynamic and current, and provides numerous opportunities for successful experiences for learning. The students' training occurs in participatory, articulate, reflective, and socially contextualized way, contributing to the formation of thorough professionals, who understand their role in society. This present paper contributes to the dissemination and spread of CL to a larger number of higher educational institutions in Brazil.

KEYWORDS: Teach-apprenticeship, Graduation courses, Interaction. 


\section{Introdução}

Considerando as mudanças constantes no perfil dos alunos de graduação, tendo em vista os avanços tecnológicos que possibilitaram a facilidade de acesso e o compartilhamento de informações, em nível mundial, é imprescindível que a atividade docente seja continuamente reformulada, de maneira a contribuir com o processo de ensino-aprendizagem. Existem diversas evidências na literatura científica de que este processo ocorre de forma exitosa quando o docente atua como facilitador do aprendizado, permitindo que os alunos participem ativamente neste contexto, interagindo com os colegas e com o professor, para a construção o conhecimento (ALCÂNTARA et al., 2004).

No sistema tradicional, ainda bastante adotado no ensino superior brasileiro como único (ou principal) modelo didático-pedagógico, o professor é considerado o centro do processo educativo, com aulas predominantemente expositivas. Neste contexto, os alunos recebem as informações de maneira passiva e acrítica, características que podem se apresentar desfavoráveis à interação (NOGUEIRA, 2009). Entendemos que toda proposta de atividade em grupo, que estimule a colaboração entre os membros, quer seja para a resolução de problemas, como para a elaboração de projetos, ou ainda, para o desenvolvimento de qualquer outra atividade que incite nos alunos a visão crítico-reflexiva, a comunicação, a criatividade, o apoio mútuo em busca de atingir um objetivo comum, a expressão de talentos, o respeito ao outro, entre outras habilidades, é extremamente produtiva e, certamente, resulta na tão sonhada e comentada construção do conhecimento.

A esse complexo de atividades que promovem a interação positiva entre professores e alunos para facilitação do processo de ensino-aprendizagem, chamamos de Aprendizagem Colaborativa/Cooperativa (AC). As atividades empregadas na AC propõem discussão, revisão de conceitos, aceitação de diversidades, reflexão, estímulo à formulação de soluções para problemas, elaboração de projetos relacionados a ensino, pesquisa e extensão; ampliação das visões social, cultural e ambiental; motivação ao pensamento crítico e investigativo; entre outros. Tais propostas contribuem, sobremaneira, para a interdependência positiva entre os membros, tão importante e necessária para a vida profissional (ALCÂNTARA et al., 2004). Por outro lado, embora se reconheça a importância e benefícios da $\mathrm{AC}$, a mesma geralmente é negligenciada no sistema tradicional de ensino.

A AC tem sido intensivamente discutida na atualidade, embora não se trate de proposta recente, pois já vem sendo discutida e implantada em instituições de ensino mundiais desde o século XVIII (BESSA e FONTAINE, 2002; TORRES et al., 2004). No ensino superior brasileiro, estão sendo instituídas, gradativamente, diferentes metodologias de Aprendizagem Colaborativa/Cooperativa (AC), que auxiliam a utilizar a heterogeneidade dos grupos para aumentar o potencial de aprendizagem de cada membro (FELIPE, A.; 2011; BRASIL, 2013). Consideramos que este é um fator positivo à educação universitária no país, uma vez que a proposta de $\mathrm{AC}$ contribui para maior motivação e envolvimento, tanto dos docentes quanto dos alunos, no processo de aprendizagem. Com isso, os alunos percebem sua importância e responsabilidade, como futuros profissionais transformadores da sociedade. 
A justificativa da escolha do tema baseia-se na pertinência e atualidade do mesmo, bem como na necessidade de contínua divulgação/disseminação da AC, como fator motivacional para que mais instituições de ensino superior do Brasil adotem-a em seus programas educacionais, especialmente nas quais o sistema tradicional de ensino é o único arcabouço didático utilizado. Em linhas gerais, com base na relevância deste tema na área educacional, o objetivo central do presente estudo foi:

- Elencar e discutir as vantagens da Aprendizagem Colaborativa/Cooperativa (AC), como proposta de incremento educativo em cursos de graduação (Ensino Superior), no Brasil.

De maneira mais detalhada, os objetivos específicos do presente estudo foram:

- Apresentar conceitos de Aprendizagem Colaborativa/Cooperativa (AC);

- Apresentar alternativas de como promover um ambiente favorável à $\mathrm{AC}$ no ensino superior;

- Enfatizar o papel do docente como facilitador no processo de ensino-aprendizagem;

- Apresentar alternativas de como constituir um grupo exitoso de AC;

- Ressaltar a importância da utilização de recursos tecnológicos em prol da AC;

- Contribuir para que a AC seja divulgada, disseminada e aplicada nas instituições de ensino superior do Brasil, nas quais o sistema tradicional educacional é o único formato adotado no processo de ensino-aprendizagem.

Para a elaboração do presente artigo, foram estudados diferentes textos com abrangência na área, publicados nos últimos dez anos em periódicos e livros de reconhecido impacto científico, como a "Revista Diálogo Educacional"; o periódico "Educação, Sociedade e Culturas"; e os livros didáticos da coleção "Metodologia do Ensino na Educação Superior" (Ibpex, Curitiba-PR). O principal referencial teórico foi a linha de estudo de Alcântara ${ }^{1}$ e colaboradores.

\section{Revisão de literatura}

\section{As tendências pedagógicas no brasil}

Antes de discutirmos especificamente sobre AC, é importante refletirmos sobre aspectos conceituais acerca das tendências pedagógicas brasileiras. Estas foram muito influenciadas pelos momentos culturais e políticos da sociedade, pois foram levadas à luz graças aos movimentos sociais e filosóficos, e formaram a prática pedagógica do país. Os professores Libâneo (1994) e Saviani (1997) propõem a reflexão sobre as tendências pedagógicas, mostrando que as principais empregadas na educação brasileira se dividem em duas grandes linhas de pensamento pedagógico: as Tendências Liberais e as Tendências Progressistas (Figura 1). Verifica-se que, devido ao dinamismo dos aspectos educacionais, há uma mistura destas tendências na prática docente atual.

A seguir, elencamos as diferentes esferas das tendências pedagógicas nacionais, seguidas de uma breve abordagem conceitual (adaptado de FOGAÇA, 2013). 


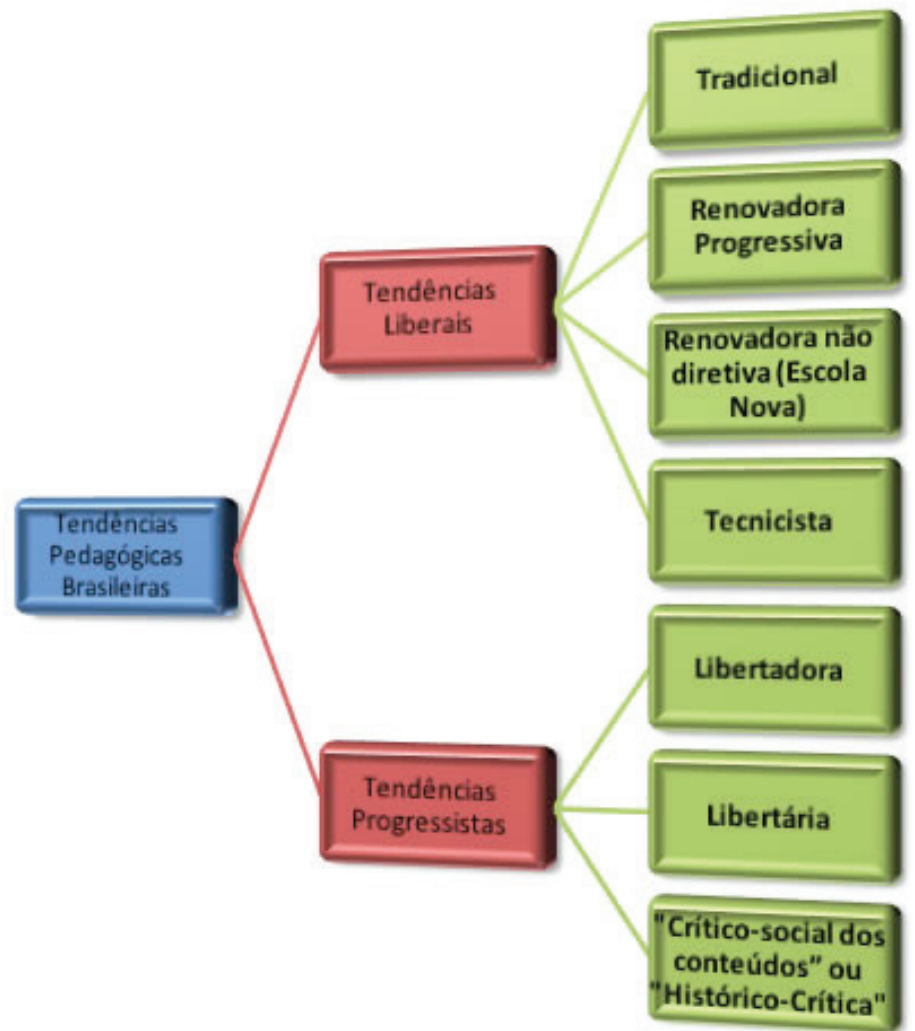

Figura 1 - Tendências pedagógicas brasileiras (Fogaça, J.). Disponível em: http://educador.brasilescola. $\mathrm{com} /$ trabalho-docente/tendencias-pedagogicas-brasileiras.htm

Tendências Liberais - não estão relacionadas à questão liberal no sentido democrático da palavra, e sim com uma instigação da sociedade capitalista (ou sociedade de classes), que sustenta a idéia de que o aluno deve ser preparado para papéis sociais de acordo com as suas aptidões, aprendendo a viver em harmonia com as normas desse tipo de sociedade. Estas tendências são fundamentadas em uma cultura individualista e competitiva.

a) Tradicional - Foi a primeira a ser instituída no Brasil por motivos históricos. Nesta tendência o professor é a figura central e o aluno é um receptor passivo dos conhecimentos considerados como verdades absolutas. Há repetição de exercícios com exigência de memorização. Os alunos temem ao professor, e não se sentem encorajados a questioná-lo. Ás avaliações são unicamente fundamentadas em provas e as "competências" dos alunos se resumem às suas respectivas notas.

b) Renovadora Progressiva - Por razões de recomposição da hegemonia da burguesia, esta foi a próxima tendência a aparecer no cenário da educação brasileira. Caracteriza-se por centralizar-SE no aluno, considerado como ser ativo e curioso. Dispõe da idéia que ele "só irá aprender fazendo"; valorizam-se as tentativas experimentais, a pesquisa, a descoberta, o estudo do meio natural e social. Aprender se torna uma atividade de descoberta, é uma autoaprendizagem. O professor é o facilitador deste processo. 
c) Renovadora não diretiva (Escola Nova) - Anísio Teixeira foi o grande pioneiro da Escola Nova no Brasil. Trata-se de um método centrado no aluno. A escola tem o papel de formadora de atitudes, preocupando-se mais com a questão psicológica do que com a social ou pedagógica. Para que um indivíduo aprenda, este deve estar significativamente ligado com suas percepções, modificando-as.

d) Tecnicista - Skinner foi o expoente principal dessa corrente psicológica, também conhecida como behaviorista. Neste método de ensino o aluno é visto como depositário passivo dos conhecimentos, que devem ser acumulados na mente através de associações. O professor é quem deposita os conhecimentos, pois ele é visto como um especialista na aplicação de manuais; sendo sua prática extremamente controlada. Articula-se diretamente com o sistema produtivo, com o objetivo de aperfeiçoar a ordem social vigente, que é o capitalismo, formando mão de obra especializada para o mercado de trabalho. No auge desta tendência, são fundadas inúmeras escolas técnicas no país.

Tendências Progressistas - Partem de uma análise crítica das realidades sociais, sustentam implicitamente as finalidades sociopolíticas da educação e é uma tendência que condiz com as idéias implantadas pelo capitalismo. $\mathrm{O}$ desenvolvimento e popularização da análise marxista da sociedade possibilitaram o desenvolvimento da tendência progressista, que se ramifica em três correntes:

a) Libertadora - Também conhecida como a pedagogia de Paulo Freire, essa tendência vincula à educação a luta e a organização de classe do oprimido. Para esse, o saber mais importante é ter consciência sobre a realidade na qual vive e sobre os problemas nela existentes. Além da busca pela transformação social, a condição de se libertar através da elaboração da consciência crítica, com sua organização de classe. Centraliza-se na discussão de temas sociais e políticos. Nesta tendência, o professor coordena atividades e atua juntamente com os alunos, estando mais aberto a discussões e reflexões.

b) Libertária - Busca a transformação da personalidade em um sentido libertário e autogestionário. Parte do pressuposto de que somente o vivido pelo educando é incorporado e utilizado em situações novas, por isso o saber sistematizado só terá relevância se for possível seu uso prático. Enfoca a livre expressão, o contexto cultural, a educação estética. Os conteúdos, apesar de disponibilizados, não são exigidos pelos alunos e o professor é tido como um conselheiro à disposição do aluno.

c) "Crítico-social dos conteúdos" ou "Histórico-Crítica" - Tendência que apareceu no Brasil nos final dos anos 70; acentua a prioridade de focar os conteúdos no seu confronto com as realidades sociais, sendo necessário enfatizar o conhecimento histórico. Prepara o aluno para o mundo adulto, com participação organizada e ativa na democratização da sociedade, por meio da aquisição de conteúdos e da socialização. O professor, neste caso, é o mediador entre os conteúdos e os alunos. Nesta tendência, o processo de ensino/aprendizagem também tem como centro o aluno. Os conhecimentos são construídos pela experiência pessoal e subjetiva.

Após a Lei de Diretrizes e Bases da Educação Nacional (LDB 9.394/96), ideias como de Piaget, Vygotsky e Wallon foram muito difundidas, tendo uma perspectiva sócio-histórica. Estas ideias são interacionistas, ou seja, são fundamentadas no conceito de que o conhecimento se dá pela interação entre sujeito e objeto. 


\section{A ênfase nas aulas expositivas precisa ser revista e ressignificada}

Como discutido anteriormente, o sistema tradicional de ensino, que representa a primeira concepção pedagógica que surgiu a partir da consolidação do modo de produção industrial no Brasil (século XIX e início do século XX), estabeleceu ênfase no conteúdo enciclopédico, ou seja, no conhecimento já instituído e tido como verdade absoluta (SUHR; SILVA, 2010). Neste sistema, geralmente o professor é tido como detentor do conhecimento e o aluno um ser passivo, que apenas absorve os conhecimentos do mestre (NOGUEIRA, 2009). Neste formato de ensino:

O docente tinha o papel de organizar os saberes em sequência lógica e transmiti-los, geralmente, por meio da exposição oral aos alunos - sem questionamento. Ele era tido, de certo modo, como centro do processo de ensino, já que definia o que e como ensinar, em que ritmo e com qual nível de exigência. (SUHR; SILVA, p. $30,2010)$

Dessa forma, estimulava-se o trabalho individual, desfavorecendo a comunicação e a cooperação entre os alunos, havendo ênfase na competição. "Questionar" a informação fornecida significaria uma afronta ao próprio mestre que a professava (SUHR e SILVA, 2010). Por este motivo, o pensamento crítico dos alunos não era desenvolvido, e os mesmos deveriam "obedecer" e respeitar a autoridade absoluta do professor em sala de aula. Entendemos que neste modelo, os alunos temiam ao professor, considerando-o como um ser intocável, intolerante e distante.

Para agravar esse distanciamento entre professor e alunos, os métodos de avaliação eram concentrados unicamente em provas, e o desempenho dos alunos era resumido a notas. Os alunos se esforçavam em conseguir atingir ao menos a nota mínima necessária para aprovação, decorando as matérias específicas para as provas, não participando ativamente do processo de construção do conhecimento (NOGUEIRA, 2009). Neste contexto, consideramos que a discriminação foi bastante disseminada, principalmente contra aqueles alunos com dificuldades de aprendizado. Estes, por não conseguirem atingir as notas mínimas necessárias para aprovação, eram denominados "incapazes" ou "débeis", sendo então desestimulados, o que os levava, inclusive, à evasão escolar. É de fácil compreensão, portanto, que este método de ensino possui limitações.

Embora historicamente o formato "tradicional" seja típico da era industrial, é possível verificar vários reflexos dessa concepção na atualidade, inclusive nas instituições de ensino superior brasileiras. "Parte dos alunos de ensino superior ainda espera do professor uma postura autoritária capaz de impor disciplina em sala, a transmissão oral de certos conceitos e sabedorias, a cobrança do silêncio e a obediência" (SUHR; SILVA, p. 31, 2010). Por outro lado, considerando os avanços tecnológicos que possibilitaram a facilidade de acesso e o compartilhamento de informações, o perfil dos alunos tem mudado. São eles que exigem dos professores aulas mais interativas; se organizam em grupos de estudo, diretórios acadêmicos, colegiados e em representações discentes junto à instituição de ensino, colaborando e opinando inclusive em questões administrativas universitárias. Os alunos, cada vez mais tem apresentado pensamento crítico e reflexivo; sendo politicamente participativos e estado preocupados em propor soluções para problemas ambientais e sociais. 
Com efeito, é inegável a necessidade de reformulação e ressignificação das aulas puramente expositivas nas Universidades e Faculdades Brasileiras. Os corpos administrativos e técnicos, das instituições de ensino superior, têm papel fundamental para que mudanças positivas ocorram em benefício do processo de ensino-aprendizagem. Uma destas propostas de melhorias seria a inclusão de métodos de Aprendizagem Colaborativa/Cooperativa (AC) nos Programas curriculares destas instituições de cursos de graduação, proporcionando ambientes de interação positiva entre os alunos e os docentes, e contribuindo para que todos participem ativamente na construção do conhecimento.

\section{Conceitos e vantagens da aprendizagem colaborativa/cooperativa (ac)}

O conceito de $\mathrm{AC}$, isto é, de aprender a trabalhar em grupo, embora pareça novo, tem sido testado e implementado por teóricos, pesquisadores e educadores desde o século XVIII (BESSA e FONTAINE, 2002; TORRES et al., 2004). Os autores que discutem e aplicam a colaboração citam as contribuições da teoria de Vygotsky como uma sustentação teórica para a $\mathrm{AC}$, ou seja, o aluno só aprende se for submetido a situações de aprendizagem (SIQUEIRA; ALCÂNTARA, 2003). Trata-se, portanto, de metodologia construtivista, onde os membros do grupo se ajudam mutuamente e confiam uns nos outros para atingir um objetivo acordado. A AC estimula a cooperação e a interação, em detrimento da competitividade e do individualismo. Neste sentido, cada membro do grupo é responsável tanto pela sua aprendizagem quanto pela do restante do grupo, ou seja, o êxito do grupo depende de cada um e de todos. Pode reunir pessoas em grupos de forma presencial ou virtual (ALCÂNTARA et al., 2004).

Entendemos que essa maneira de pensar e agir já esteja bastante incutida na sociedade atual. Os comportamentos, hábitos e práticas das pessoas no mundo todo apresentam uma tendência ao menor individualismo, ao menor consumismo, à maior preocupação com o outro e com o meio ambiente, ao respeito às diferenças, à preservação/promoção da coletividade. Isto tem se refletido em diversos âmbitos - religioso, político, cultural, social, econômico - e não seria diferente no meio acadêmico. No ambiente universitário, o estudante tem à disposição uma infinidade de recursos a serem explorados para seu aprendizado, e ele se sente ainda mais motivado quando trabalha em atividades interativas e de cooperação.

Quando retornamos às origens da fundamentação conceitual da $\mathrm{AC}$, não podemos deixar de citar os estudiosos Piaget e Vygotsky. A epistemologia genética de Piaget tem como foco principal o sujeito epistêmico, ou seja, o sujeito que constrói conhecimentos. Piaget parte da relação entre o sujeito e o objeto (meio físico e social), postulando que estes estabelecem contínuas relações entre si, em que um constitui o outro mutuamente (Nogueira, 2009). Segundo Piaget (1978), "a adaptação intelectual é o equilíbrio entre a assimilação da experiência às estruturas (mentais) dedutivas e a acomodação dessas estruturas aos dados da experiência". Da mesma forma, o professor e pesquisador Vygotsky (1991), afirma que "embora os conceitos não sejam assimilados prontos, o ensino escolar desempenha um papel importante na formação dos conceitos de um modo geral e dos científicos em particular, (...) possibilita que o indivíduo tenha acesso ao conhecimento cientificamente construído e acumulado pela humanidade". Dessa forma, entendemos que o ambiente escolar/universitário é de fundamental importância para que ocorram as interações necessárias que possibilitam ao estudante 
aprender e amadurecer, pois ele estará em contato com diferentes alunos e professores, vivenciando experiências inéditas e preparando-se para atuar como futuro profissional.

Consideramos que a preocupação dos docentes para que houvesse uma maior participação dos alunos e, consequentemente, um processo ensino-aprendizagem mais produtivo, ocorre há muitos anos. Historicamente, no início da década de 1970, fundamentando-se em teorias sobre a organização social da aprendizagem de autores como Bremer, Moschzisker e outros autores dessa época, professores americanos chegaram à conclusão de que precisavam de uma alternativa ao método tradicional de ensino-aprendizagem, a fim de que eles pudessem oferecer uma melhor preparação aos estudantes. Assim, algumas faculdades americanas começaram a adotar técnicas de instrução e avaliação em pares e em grupos, trabalho esse classificado como AC. Nesse novo contexto, a força educativa poderosa do trabalho em grupo, tanto desperdiçada pelos métodos tradicionais de ensino, foi revitalizada pela nova postura de trabalho dos educadores. Desta forma, a década de 1970 foi de fundamental importância para o início das implantações de atividades de AC no ambiente escolar, pois, como descreve Torres (2004) apud Johnson (2002) e Gilliam (2002):

[...] houve muita produção na área de aprendizagem cooperativa e colaborativa. David Johnson escreveu Psicologia Social da Educação e Robert Hamblin desenvolveu pesquisas comportamentais sobre cooperação e competição. Ainda nos anos 70, ocorreu a primeira conferência internacional sobre aprendizagem colaborativa em Tel Aviv, Israel e também o Jornal de Pesquisa e Desenvolvimento em Educação lançou uma edição sobre cooperação.

No entanto, devemos considerar que as atividades de AC estiveram marcadamente presentes no ensino superior na década de 1990 (TORRES et al., 2004). Um fator que pode ter contribuído às atividades de $\mathrm{AC}$ é o advento da internet e de recursos digitais educativos, no mesmo período, que possibilitaram a melhor e mais rápida comunicação mundial e o acesso às informações.

Siqueira e Alcântara (2003, p. 61) reforçam que o trabalho em grupo no processo da construção do conhecimento se baseia em: "utilizar o conhecimento para confrontá-lo com a realidade ou situação problema e construir novo conhecimento a partir do debate, da troca de ideias entre os pares". Essa fundamentação contribuiu para o desenvolvimento de atividades como a "Aprendizagem Baseada em Problemas" e "Aprendizagem Baseada em Projetos", bastante disseminadas em cursos universitários no Brasil.

Como bem colocam Bessa e Fontaine (2002, p. 125):

É de realçar que este tipo de aprendizagem é benéfico para a maioria dos alunos. Com efeito, um indivíduo só poderá ser bem sucedido na realização dos seus objetivos, se os outros também o forem e vice-versa, pelo que, numa situação puramente cooperativa, encontramos uma correlação positiva perfeita entre a satisfação dos objetivos dos diferentes participantes. Contrariamente, numa estrutura competitiva assiste-se a uma correlação negativa entre a possibilidade de realização dos objetivos pelos vários participantes: nesta estrutura, a ação realizada por cada um deles pode vir a frustrar, se for bem sucedida, a satisfação dos objetivos restantes. 
Esse perfil colaborativo tem sido verificado inclusive em empresas, tanto nacionais quanto multinacionais, que aboliram a separação dos funcionários que era realizada por gabinetes fechados, e mantendo-os em mesas coletivas amplas, para facilitar a comunicação e a interação entre os mesmos. Este novo modelo estrutural tem gerado um ambiente de trabalho menos estressante e consequentemente mais produtivo.

Conceitualmente, existem algumas controvérsias com relação à definição de AC. A revisão bibliográfica sobre o tema permite constatar que frequentemente utilizam-se os termos cooperação e colaboração como sinônimos. Porém, cada um deles, ao longo dos anos, desenvolveu distinções próprias e diferentes práticas em salas de aula.

Muitos autores na literatura atual definem a aprendizagem cooperativa como uma aprendizagem mais estruturada, com técnicas de sala de aula mais prescritivas e com regras mais definidas de como deve se processar a interação entre os alunos, se comparada com a aprendizagem colaborativa. [...] Assim, a Aprendizagem Colaborativa é uma filosofia de ensino, não apenas uma técnica de sala de aula. (TORRES et al., p.130, 2004)

Apesar das diferenças conceituais e de interpretação entre os autores, vale ressaltar que, tanto a colaboração, quanto a cooperação no processo de ensino-aprendizagem estão intimamente ligadas, e são interdependentes, ou seja, para que haja colaboração é necessário que ocorra a cooperação entre os membros do grupo.

Para facilitar a compreensão das definições de cooperação e colaboração, segundo diferentes autores, foram elaborados os Quadros 1a e 1b, como segue:

Quadro 1a. Definições de aprendizagem colaborativa/cooperativa segundo as visões de diferentes autores.

\begin{tabular}{|c|c|c|}
\hline Autor/Ano & Aprendizagem Cooperativa & Aprendizagem Colaborativa \\
\hline $\begin{array}{l}\text { Kagan } \\
(1989, \\
1990)\end{array}$ & $\begin{array}{l}\text { Baseada na criação, análise e apli- } \\
\text { cação sistemática de estruturas, ou } \\
\text { formas de organização da intera- } \\
\text { ção social em sala de aula. Normas } \\
\text { bem definidas; interatividade entre } \\
\text { grupos de alunos; objetivo comum } \\
\text { relativo ao conteúdo proposto. }\end{array}$ & \\
\hline $\begin{array}{l}\text { Paas (1999) } \\
\text { apud } \\
\text { Harassim } \\
(1995)\end{array}$ & & $\begin{array}{l}\text { Qualquer atividade na qual duas } \\
\text { ou mais pessoas trabalham juntas } \\
\text { para criar significado, explorar um } \\
\text { tópico ou melhorar habilidades. }\end{array}$ \\
\hline $\begin{array}{l}\text { Mathews et } \\
\text { al. (1995) }\end{array}$ & & $\begin{array}{l}\text { Engloba questões teóricas, } \\
\text { políticas e filosóficas tais como a } \\
\text { natureza do conhecimento como } \\
\text { uma construção social e o papel da } \\
\text { autoridade na sala de aula. }\end{array}$ \\
\hline
\end{tabular}


Continuação Quadro 1a

\begin{tabular}{|c|c|c|}
\hline $\begin{array}{l}\text { Panitz } \\
(2003)\end{array}$ & $\begin{array}{l}\text { Estrutura de interação projetada } \\
\text { para facilitar a realização de um } \\
\text { objetivo ou produto final. É um } \\
\text { processo mais direcionado do que } \\
\text { o processo de colaboração e mais } \\
\text { controlado pelo professor. }\end{array}$ & $\begin{array}{l}\text { Filosofia de interação e um estilo } \\
\text { de vida pessoal. O aluno possui um } \\
\text { papel mais ativo. }\end{array}$ \\
\hline $\begin{array}{l}\text { Daele } \\
\text { (1998) }\end{array}$ & & $\begin{array}{l}\text { Modelo de aplicação pedagógica } \\
\text { de internet que visa favorecer a } \\
\text { colaboração entre pares por meio } \\
\text { de troca de mensagens eletrônicas } \\
\text { entre os estudantes de um grupo ou } \\
\text { de uma classe. }\end{array}$ \\
\hline $\begin{array}{l}\text { Nitzke et al. } \\
\text { (1999) apud } \\
\text { Larocque } \\
\text { (1997) e } \\
\text { Dillenbourg } \\
\text { (1999) }\end{array}$ & $\begin{array}{l}\text { A estrutura hierárquica prevalece } \\
\text { e cada um dos membros da equipe } \\
\text { é responsável por uma parte da } \\
\text { tarefa. }\end{array}$ & $\begin{array}{l}\text { Todos trabalham em conjunto, sem } \\
\text { distinções hierárquicas, em um es- } \\
\text { forço coordenado, a fim de alcançar } \\
\text { o objetivo ao qual se propuseram. }\end{array}$ \\
\hline Paas (1999) & $\begin{array}{l}\text { A coordenação é apenas obriga- } \\
\text { tória na montagem dos resultados } \\
\text { parciais. }\end{array}$ & $\begin{array}{l}\text { Atividade coordenada, sincroniza- } \\
\text { da, que é resultado de um esforço } \\
\text { continuado de construir e manter } \\
\text { uma concepção compartilhada de } \\
\text { um problema. }\end{array}$ \\
\hline
\end{tabular}

Fonte: Adaptado do texto de TORRES et al. (2004)

Quadro 1b. Definições de aprendizagem colaborativa/cooperativa segundo as visões de diferentes autores.

\begin{tabular}{|c|c|c|}
\hline Autor/Ano & Aprendizagem Cooperativa & Aprendizagem Colaborativa \\
\hline $\begin{array}{l}\text { Cunha } \\
\text { Filho et al. } \\
(2000)\end{array}$ & $\begin{array}{l}\text { Além da relação entre sujeitos é } \\
\text { acrescida a possibilidade de coo- } \\
\text { peração entre eles e as entidades } \\
\text { de software (os agentes), transfor- } \\
\text { mados em elementos facilitadores } \\
\text { do processo de comunicação e } \\
\text { aprendizagem em comunidades } \\
\text { virtuais de grande porte. }\end{array}$ & \\
\hline Cord (2000) & & $\begin{array}{l}\text { Designa-se, de uma parte, a coope- } \\
\text { ração entre os membros da equipe } \\
\text { e, de outra, a realização de um pro- } \\
\text { duto final. A internet apresenta-se } \\
\text { neste tempo como a ferramenta } \\
\text { adequada para colocar em opera- } \\
\text { ção as pedagogias colaborativas. } \\
\text { Depende da cooperação entre os } \\
\text { membros da equipe. }\end{array}$ \\
\hline $\begin{array}{l}\text { Torres et al. } \\
\text { (2004) }\end{array}$ & & $\begin{array}{l}\text { Qualquer atividade desenvolvida } \\
\text { em conjunto animada por um obje- } \\
\text { tivo final que leve a aquisições de- } \\
\text { terminadas. Processo de reacultu- } \\
\text { ração que ajuda os estudantes a se } \\
\text { tornarem membros de comunida- } \\
\text { des de conhecimento cuja proprie- } \\
\text { dade comum é diferente daquelas } \\
\text { comunidades que já pertencem. }\end{array}$ \\
\hline
\end{tabular}

Fonte: Adaptado do texto de TORRES et al. (2004) 
A AC auxilia no ingresso e na permanência dos estudantes na Universidade, pois estimulam os alunos a estudar em grupo e não depender somente do professor; construindo uma autonomia intelectual. Os estudantes que conseguem ingressar na Universidade servem de exemplo e de valorização para o grupo. A Aprendizagem Cooperativa se importa com o fortalecimento do jovem como protagonista da sociedade. Dentro deste contexto, vale ressaltar que no Brasil existem diversas iniciativas, como o Programa de Educação em Células Cooperativas (Prece) ${ }^{2}$. No Ceará existe a Escola Popular Cooperativa (EPC), onde os estudantes que fizeram parte do Programa e ingressaram no ensino superior retornam à comunidade para facilitar o processo de aprendizagem (ASSUNÇÃO, 2012). Em 2012, o Programa concedeu bolsas para 250 estudantes dos mais diversos cursos da Universidade Federal do Ceará (UFC) para montar um grupo na Universidade utilizando a Aprendizagem Cooperativa. Nos grupos, os participantes trocam conhecimentos e experiências, servindo de ajuda mútua para superar as dificuldades de permanência na instituição.

Atualmente, projetos de parceria entre a UFC, Prece e Secretarias Municipais de Educação também levam a experiência da metodologia para escolas públicas do Ceará, com o objetivo de valorizar a $\mathrm{AC}$ e ajudar os estudantes a ingressarem na Universidade. No curso superior, a AC auxilia, inclusive, no fortalecimento dos vínculos de amizade entre os alunos; troca de conhecimentos e experiências, servindo de ajuda mútua para superação das dificuldades de permanência na instituição, evitandose a evasão (ASSUNÇÃO, 2012).

$\mathrm{O}$ método de $\mathrm{AC}$ apresenta diversas vantagens, entre elas:

a) Constitui proposta inovadora, em relação aos métodos tradicionais de ensino, que determinavam a centralização do professor (ou do aluno) no processo de ensino-aprendizagem. $\mathrm{Na}$ Aprendizagem Colaborativa, são valorizadas as relações dentro de cada grupo de alunos; entre os grupos; e entre os grupos e o professor (TORRES et al., 2004);

b) Contribui para que o professor atue como facilitador no processo ensino -aprendizagem, e os alunos participem ativamente na construção do conhecimento. No entanto, é fundamental o papel do professor no trabalho, pois cabem a ele as indagações, questionamentos e acompanhamento das atividades dos grupos (NOGỦEIRA, 2009);

c) Permite que os alunos se tornem autônomos, articulados e socialmente amadurecidos, reduzindo o pensamento individualista e competitivo e ampliando a reflexão para o coletivo (o "olhar para o outro") (SUHR; SILVA, 2010);

d) Possibilita a experiência do trabalho em grupo, por meio da interação face -a-face; da contribuição individual; do manejo da heterogeneidade; do desenvolvimento de habilidades interpessoais e da interdependência positiva; fatores necessários para a vida profissional futura dos alunos (SIQUEIRA; ALCÂNTARA, 2003);

e) Contribui para o compartilhamento dos saberes individuais, buscando atingir os objetivos do grupo, por meio da resolução de problemas reais e a elaboraçã̃o de propostas que sejam aplicáveis na prática (ALCÂNTARA et al., 2004);

f) Permite maior motivação dos alunos; com relação dialógica exitosa, visando ao aprendizado diferenciado e efetivo, em menor tempo, comparado com métodos de ensino conservadores (NOGUEIRA, 2009). 
Como se pode verificar, as vantagens e benefícios que a $\mathrm{AC}$ proporciona ao processo de ensino-aprendizagem são evidentes e indiscutíveis. Não se pode conceber que, nos dias atuais, frente a todas as inovações tecnológicas e científicas que ocorrem diariamente, e considerando que o perfil do alunado acompanha estas transformações com a mesma velocidade e intensidade, ainda existam instituições de ensino superior no Brasil que não utilizem os métodos de $\mathrm{AC}$ em seus Programas curriculares.

\begin{abstract}
Nessa medida, é importante que a escola pare com um tipo de ensino que reproduz relações de hierarquia e subordinação, substituindo-os por modos de ensino alternativos. Modos de ensino que concedam aos indivíduos a capacidade de agirem coletiva e democraticamente. (BESSA; FONTAINE, p. 143, 2002)
\end{abstract}

Vale ressaltar que, quando as vantagens da $\mathrm{AC}$ são evidenciadas no presente artigo, não se pretende afirmar ser esta a única (ou a melhor) metodologia didática a ser utilizada no processo de ensino-aprendizagem, e sim recomendá-la como fomento educacional em instituições de ensino superior, como um incremento aos Programas tradicionais de ensino.

\title{
O envolvimento docente
}

O papel do professor na proposta de $\mathrm{AC}$ é de fundamental importância. Como relatado anteriormente, ele deve atuar como mediador para que ocorra a construção do conhecimento entre os alunos. Para tanto, é necessário que o docente conheça as diferentes possibilidades e meios de aplicação da proposta, além de apresentar estratégias, planejamento e motivação (MELO; URBANETZ, 2009).

Entendemos que para que o processo de AC ocorra de forma exitosa, o docente deverá sentir-se motivado e comprometido, e que compreenda a proposta e suas possibilidades de aplicação. $\mathrm{O}$ docente deverá acreditar neste processo e ter, à sua disposição e de seus alunos, adequado suporte material (e técnico, se for o caso), para a implantação das atividades. Da mesma forma, o docente deverá atuar como motivador dos alunos, para que os mesmos compreendam e se envolvam com a proposta. Sem o comprometimento e interação de todos (alunos e professor), e se não houver o entendimento do "por que fazer" as chances de insucesso e frustração serão altas (SIQUEIRA; ALCÂNTARA, 2003).

Quando consideramos o ponto de vista técnico-estrutural necessário para a implantação e condução de atividades de $\mathrm{AC}$ no ambiente universitário, entendemos que devam ser oferecidos treinamentos ao corpo docente, visando ao fornecimento de informações, esclarecimento de dúvidas, apresentação dos recursos disponíveis para a realização das atividades, etc. Esse treinamento, se possível ministrado ou gerido por corpo técnico pedagógico, proporcionaria maior visibilidade dos docentes com relação ao tema, tendo em vista que nem todos os professores, das mais variadas áreas de atuação, estão familiarizados com diferentes propostas pedagógicas. Entendemos, ainda, que estes treinamentos devam ocorrer de forma periódica, para que se possibilite inclusive a discussão de pontos que podem ser melhorados para que o processo de $\mathrm{AC}$ ocorra de forma produtiva e contribua para a interação positiva entre docentes e alunos, para a construção do conhecimento. 
Por outro lado, cada docente poderá continuamente se atualizar e capacitar, buscando participar de cursos e eventos relacionados à área, de maneira a trazer novas propostas pedagógicas ao seu programa de ensino. Ele poderá também fazer um balanço após o término de cada atividade com os alunos, buscando aperfeiçoar a metodologia para futuras aplicações com outras turmas (MELO; URBANETZ, 2009).

Vale ressaltar que a colaboração mútua entre os docentes é extremamente desejável, e pode contribuir para que ocorram propostas de $\mathrm{AC}$ interdisciplinares. Tais propostas auxiliam na ampliação da visão dos alunos, que em vias gerais é tão prejudicada pela segmentação e departamentalização do ensino. Compreender "o todo" possibilita que os alunos se tornem profissionais maduros e articulados (NOGUEIRA, 2009). A interação entre os docentes de diferentes áreas pode proporcionar a condução, por exemplo, de projetos temáticos de pesquisa e/ou extensão, com o envolvimento de alunos e de técnicos, visando a propor soluções para problemas da sociedade. Dessa forma, seria oferecida aos alunos a oportunidade de conhecer e compreender a realidade na qual vivem e construir, com base em uma visão crítico-reflexiva, o conhecimento e a motivação para fazer a diferença.

\section{Como estabelecer um bom grupo de aprendizagem?}

Para que ocorra a AC é necessário um ambiente que permita adequada comunicação e interação entre os envolvidos. Devem-se disponibilizar, aos alunos, todos os recursos e materiais necessários para o bom desenvolvimento dos trabalhos. Este ambiente não pode (e não deve) ficar restrito à sala de aula - embora seja o mais comum que se dispõe para o encontro com os alunos. Outras possibilidades envolvem os laboratórios de informática, as bibliotecas, o laboratório de experimentos (SIQUEIRA; ALCÂNTARA, 2003), e quaisquer ambientes favoráveis à interação.

O docente poderá, antes de iniciar as atividades com os alunos, apresentar a proposta e elucidá-la. Pode ser necessário treinamento prévio para a compreensão dos processos grupais (MELO; URBANETZ, 2009). Também poderá atuar como facilitador, elencando temas para as discussões e sugerindo alternativas, sem impor soluções aos grupos. Deve ser ressaltada a responsabilidade e comprometimento de cada membro com o objetivo que é definido e compreendido pelo grupo. "As propostas e ação pedagógica requerem uma profunda reflexão do professor, que necessita aproximar-se do aluno, [...] garantindo sua adesão ao programa" (SIQUEIRA; ALCÂNTARA, 2003, p. 59).

Os grupos devem ser constituídos por número reduzido de alunos (de três a cinco indivíduos). Grupos maiores geralmente apresentam dificuldades para manter todos os membros envolvidos. $\mathrm{O}$ docente deverá designar os grupos, permitindo a heterogeneidade (níveis diferentes de habilidades, formação, experiência). Estes funcionam melhor do que os grupos que se formam por si mesmos. A aprendizagem é influenciada positivamente com a diversidade de perspectivas e experiências:

São as atividades que dão sentido à ação do grupo ao mesmo tempo em que o dinamizam. É no processo de gestão destas atividades que os componentes do grupo se organizam, repartem papéis, discutem ideias e posições, interagem entre si, definem subtarefas, tudo isso, dentro de uma proposta elaborada, definida e negociada coletivamente. (TORRES et al., p. 131, 2004) 
Deve-se considerar que poderá haver problemas com determinados grupos, por diferentes causas: dificuldade de relacionamento entre os membros; falta de estímulo de um ou mais membros; falta de comprometimento e/ou de interesse. Avaliações confidenciais entre pares são uma boa forma de analisar quem está ou não contribuindo. $\mathrm{O}$ docente poderá também permitir que o grupo exclua um membro não cooperativo ou não participante, se todas as medidas tomadas foram em vão. De outra maneira, os indivíduos poderão sair do grupo se acreditarem que estão realizando a maior parte do trabalho com pouca ajuda dos outros (essa pessoa, em geral, pode facilmente encontrar outro grupo que acolha suas contribuições). Os grupos com problemas deverão ser solicitados a encontrar com o docente para discutir possíveis soluções (ALCÂNTARA et al., 2004).

Os princípios e responsabilidades operacionais devem ser compartilhados, definidos e acordados por cada membro. Incluem-se neles:

1. Manter discussões e desacordos focados nos temas, evitando críticas pessoais; 2. Esquematizar revisão do progresso e comunicação para discutir o que está funcionando e o que não está;

(ALCÂNTARA et al., 2004)

3. Ter responsabilidade para a divisão de tarefas e realizá-las a contento. Caso o aluno apresente dificuldades, poderá ser estimulado a aceitar o desafio; e realizar as tarefas com a ajuda dos demais colegas e do professor;

(SIQUEIRA; ALCÂNTARA, 2003)

4. O comprometimento em participar, preparar e chegar no horário marcado para as reuniões;

5. Estabelecer com que frequência e de que forma será realizada a comunicação, a avaliação do progresso, a tomada de decisões e a resolução de conflitos;

6. Definir fontes de informação (diretrizes, supervisão, aconselhamento, e até decisão);

7. Ao finalizar o trabalho, o grupo deverá avaliar a forma como o mesmo foi conduzido, elencando os pontos positivos e negativos ocorridos durante o processo; além de concluir se os objetivos foram atingidos. Em caso negativo, os membros devem se articular e refletir sobre as possíveis falhas, propondo alternativas para a reformulação do projeto e/ou resolução dos problemas. Desta forma, serão desenvolvidas habilidades como: pró-atividade, pensamento crítico e reflexivo, criatividade, auto-avaliação, projeção, motivação, organização, análise, síntese, entre outras.

(MELO; URBANETZ, 2009)

A apresentação dos resultados obtidos em grupo, ao final do trabalho, são imprescindíveis para o processo de AC:

Em qualquer um dos ambientes de aprendizagem, ao término da atividade, como complemento à avaliação, deve ocorrer a expressão da síntese, organizada pelo pensamento, que poderá ser exposta por uma apresentação oral para o grupo, ou por textos, painéis, ou mesmo por programas de computador dedicados a uma função educativa específica. (SIQUEIRA; ALCÂNTARA, p. 65, 2003) 
Com isso, os alunos têm a visão completa da condução de um projeto desde a elaboração da proposta até a conclusão. Este aprendizado os auxiliará não somente em suas atividades profissionais futuras, como também em tomadas de decisões em suas vidas pessoais, ou seja, é um aprendizado que extrapola as barreiras da sala de aula.

\section{A tecnologia em prol da aprendizagem colaborativa}

A tecnologia tem auxiliado em diversas propostas de $\mathrm{AC}$, permitindo a combinação de diferentes métodos de ensino e aprendizagem:

Com a disseminação das tecnologias de informação e comunicação (TIC), emergiu um novo conceito identificado pelo b-learning (blended-learning), onde a aprendizagem é um processo contínuo, deixando de estar constrangido a um só contexto, espaço ou a um dado momento. Através do b-learning os alunos dispõem (on-line e face-a-face) de novas oportunidades de aprendizagem, podendo escolher ou combinar as ofertas das unidades curriculares consoantes às suas reais necessidades. (MATEUS FILIPE; ORVALHO, p. $217,2004)$

Segundo Torres et al. (2004, p. 131), "a tecnologia oferece meios que facilitam o processo de cooperação e colaboração, seja ele educativo, seja ele do campo laboral".

$\mathrm{Na}$ Web, está disponível o acesso gratuito e/ou compartilhamento de vasta quantidade de materiais educativos, de ampla abrangência, variedade e qualidade, permitindo a interação colaborativa. Instituições de ensino a distância (Ead), em sua grande maioria, trabalham com plataformas eletrônicas que possibilitam o compartilhamento de informações/textos e vídeos educativos, além de fóruns de discussão e outras formas de interação (ROCHA, 2009).

Outras opções envolvem o uso de softwares interativos que podem ser utilizados em atividades de grupos, para resolução de problemas, elaboração de projetos, construção do saber, entre outros. Neste caso, recomenda-se que os grupos sejam formados por um número menor de alunos, para que haja melhor aproveitamento em termos de aprendizagem.

O sistema on-line de ensino tem sido relatado, pelos próprios alunos, como um estreitador de laços entre si e entre o professor, pois, por meio de fóruns e outros canais de conversa, alguns estudantes conseguem elucidar dúvidas de questões que, por timidez ou receio, não dirigiriam ao professor em sala de aula (ROCHA, 2009).

No sistema b-learning ${ }^{3}$, também pode ser permitida aos alunos a possibilidade de monitoramento da avaliação individual, para que visualizem seus progressos nas atividades propostas podendo, a todo o momento, corrigir e/ou superar níveis de desempenho e de pedir apoio e esclarecimentos ao professor. Neste caso, o papel de facilitador do processo ensino/aprendizagem adotado pelo professor, pode ser classificado como e-moderação, com todas as vantagens elencadas anteriormente. 


\section{Considerações finais}

Apesar dos avanços tecnológicos e científicos que permitem o acesso rápido a informações em nível mundial, e considerando a progressiva alteração do perfil dos alunos dos cursos de graduação, o sistema de ensino tradicional, com aulas puramente expositivas, ainda tem sido adotado como o principal modelo didático-pedagógico no ensino superior brasileiro. Este formato apresenta desvantagens, particularmente no que diz respeito à menor possibilidade de interação e de um espírito crítico-reflexivo.

O dinamismo atual das questões econômicas, sociais, culturais e educacionais demanda uma reformulação urgente deste modelo. $\mathrm{O}$ aluno já ingressa à universidade com certa maturidade e caráter crítico, e não se contenta mais com o modelo de ensino centrado no professor e/ou nos conteúdos. Neste contexto, a Aprendizagem Colaborativa/Cooperativa (AC), que se trata de uma proposta construtivista com inúmeras vantagens pedagógicas, constitui incremento educacional importante, especialmente no âmbito do ensino superior. Neste modelo, a interação entre os docentes e os alunos é continuamente estimulada, assim como o trabalho em grupo, o raciocínio coletivo buscando a resolução de problemas reais, a comunicação, o respeito à personalidade de cada membro, a criatividade, a reflexão, entre inúmeras outras habilidades.

Por outro lado, entendemos que para que esta proposta seja coroada com êxito no ambiente universitário, é de fundamental importância que todos os envolvidos no processo de AC (docentes, alunos, técnicos, gestores, etc.) devam, minimamente: conhecer a proposta, estar motivados a desenvolvê-la, contribuir para melhorias, e ter à sua disposição os recursos necessários para tal.

É imprescindível destacar que os recursos tecnológicos, atualmente disponíveis, têm facilitado a comunicação mundial, e a disponibilização da informação em tempo real, vencendo as barreiras físicas e contribuindo para a maior agilidade no acesso aos conteúdos. Tais recursos, quando utilizados em propostas de $\mathrm{AC}$, colaboram sobremaneira para a interação entre os docentes e os alunos, estimulando o raciocínio, o pensamento crítico-reflexivo e o espírito de colaboração e de trabalho em grupo.

Após criteriosa revisão de literatura sobre o tema, não encontramos nenhum relato de experiência mal sucedida de AC. Em todos os artigos e capítulos de livro estudados, verificam-se inúmeras vantagens de sua implantação, que proporciona a interação positiva entre docentes e alunos, para a construção do conhecimento, bem como o crescimento das instituições de ensino como um todo.

Com base nas considerações apresentadas, no presente artigo, verifica-se que a $\mathrm{AC}$ é factível, dinâmica e atual, proporcionando inúmeras possibilidades de experiências exitosas para o aprendizado. A formação dos alunos ocorre de maneira participativa, articulada, reflexiva, e socialmente contextualizada, contribuindo para a formação de profissionais completos, que compreendem seu papel na sociedade. Dessa forma, conclui-se que o presente artigo contribui para a divulgação e disseminação da $\mathrm{AC}$ para um maior número de instituições de ensino superior brasileiras. 


\section{Referências}

ALCÂNTARA, P. R.; MARQUES SIQUEIRA, L. M.; VALASKI, S. Vivenciando a aprendizagem colaborativa em sala de aula: experiências no ensino superior. Revista Diálogo Educacional, v. 4, n.12, p. 1-20, 2004.

ASSUNÇÃO, K. Aprendizagem colaborativa ajuda no ingresso e na permanência de estudantes na Universidade. Adital. Disponível em: <http://www.adital.com.br/jovem/noticia_imp.asp?lang=PT\&img=N\&cod=63471> Acesso em: 20 ago. 2012.

BESSA, N.; FONTAINE, A.M. A aprendizagem cooperativa numa pós-modernidade crítica. Educação, Sociedade e Culturas, n. 18, p. 123-147, 2002.

BRASIL. Ministério da Educação. Coordenação de Aperfeiçoamento de Pessoal de Nível Superior. Universidade Aberta do Brasil - Instituições. Disponível em: <http://www.uab.capes. gov.br/index.php?option=com_wrapper\&view=wrapper\&Itemid=10> Acesso em: 01 ago. 2013.

FELIPE, A. A. C. Ciência da informação e ambientes colaborativos de aprendizagem: um estudo de caso da Plataforma Moodle - UFPB. Dissertação (Mestrado em Ciência da Informação) - Curso de Ciência da Informação, Universidade Federal da Paraíba, 2011. 154p.

FOGAÇA, J. Tendências pedagógicas brasileiras. Disponível em: <http://educador.brasilescola.com/trabalho-docente/tendencias-pedagogicas-brasileiras.htm> Acesso em: 31 jul. 2013.

LIBÂNEO, J.C. Didática. São Paulo: Editora Cortez. 1994.

MATEUS FILIPE, A. J.; ORVALHO, J. G. Blended-Learning e Aprendizagem Colaborativa no Ensino Superior. In: VII Congresso Iberoamericano de Informática Educativa, p. 216225,2004

MELO, A.; URBANETZ, S.T. Organização e estratégias pedagógicas. Curitiba: Ibpex, 2009 (Coleção Metodologia do Ensino na Educação Superior, v. 8), 204p.

NOGUEIRA, M.O.G. Aprendizagem do aluno adulto: implicações para a prática docente no Ensino Superior. Curitiba: Ibpex, 2009 (Coleção Metodologia do Ensino na Educação Superior, v.4), 144p.

PIAGET, J. A epistemologia genética: sabedoria e ilusões da filosofia; problemas de psicologia genética. Tradução de Nathanael C. Caixeiro, Zilda A. Daeir e Célia E.A. Di Pietro. São Paulo: Abril Cultural, 1978. (Coleção Os Pensadores).

ROCHA, C.A. Mediações tecnológicas na Educação Superior. Curitiba: Ibpex, 2009 (Coleção Metodologia do Ensino na Educação Superior, v. 5), 198p.

SAVIANI, D. Pedagogia Histórico-Crítica: primeiras aproximações. 6a Edição. Coleção Polemicas do Nosso Tempo. Campinas: Editora Autores Associados, 1997.

SIQUEIRA, L. M. M.; ALCÂNTARA, P. R. Modificando a atuação docente utilizando a colaboração. Revista Diálogo Educacional, v. 4, n. 8, p. 1-13, 2003.

SUHR, I. R. F.; SILVA, S. Z. Relação professor-aluno-conhecimento. Curitiba: Ibpex, 2010 (Coleção Metodologia do Ensino na Educação Superior, v. 7), 139p.

TORRES, P. L.; ALCÂNTARA, P. R.; FREITAS IRALA, E. A. Grupos de consenso: uma proposta de aprendizagem colaborativa para o processo de ensino-aprendizagem. Revista Diálogo Educacional, v. 4, n. 13, p. 1-17, 2004.

VYGOTSKY, L. S. A formação social da mente. 4. ed. São Paulo: M. Fontes, 1991. 


\section{Notas}

${ }^{1}$ Paulo Roberto Alcântara: Ph.D. em Desenvolvimento Humano e Mestre em Educação pelo George Peabody College of Vanderbilt University, professor do Programa de Mestrado em Educação da PUCPR,coordenador da Linha de Pesquisa Educação, Comunicação e Tecnologia e professor da Graduação em Pedagogia da PUCPR. Rua Imaculada Conceição, 1155, Prado Velho, Curitiba- PR, CEP 80.215-901. paulo.alcantara@pucpr.br

${ }^{2}$ A experiência da Prece surgiu em 1994 na comunidade de Cipó (Ceará), onde estudantes se reuniam para estudar em "uma velha casa de fazer farinha”. A Universidade Federal do Ceará adotou este projeto, que foi oficializado como Programa de Educação em Células Cooperativas. Os estudantes que fizeram parte deste Programa e que conseguiram ingressar em universidades retornam à comunidade para facilitar o processo de aprendizagem e motivar os demais jovens. Desta forma, os universitários também são estimulados a permanecer na Universidade, reduzindo os índices de evasão.

${ }^{3}$ b-learning: blended-learning termo em lingua inglesa, normalmente relacionado à Educação à Distância, que pode ser compreendido como ensino semi-presencial ou ensino híbrido. $\mathrm{O}$ verbo blend em língua inglesa significa misturar, combinar. Esta forma de ensino, portanto, combina estudo presencial com estudo à distância. Fonte: VILAÇA, M. "O que é blended learning?” em: Ensino Atual - Educação, Linguagem e Tecnologia. Disponível em: <http://ensinoatual.com/blog/?p=343> Acesso em: 27/09/2012.

* Pós-doutoranda pela Faculdade de Medicina Veterinária e Zootecnia da Universidade Estadual Paulista Júlio de Mesquita Filho, Botucatu, São Paulo - Brasil.

*** Mestre em Educação e Doutorando em Educação pela Universidade Tuiuti do Paraná, Curitiba, Paraná - Brasil.

\section{Correspondência}

Marcella Zampoli Troncarelli - Universidade Estadual Paulista Júlio de Mesquita Filho, Distrito de Rubião Junior, s/n. CEP: 18618-970, Botucatu, São Paulo - Brasil.

E-mail: matroncarelli@yahoo.com.br-matroncarelli@yahoo.com.br

Recebido em 31 de janeiro de 2013

Aprovado em 06 de agosto de 2013 